\title{
Escritura escénica y Posmodernidad
}

\author{
Mariastella CASSELLA \\ Universidad de Alcalá de Henares \\ mariastellacassella@gmail.com
}

\begin{abstract}
RESUMEN
Hablar de escritura escénica significa mostrar el carácter de pluricódigo y de plurimaterialidad que tiene el hecho teatral, así como dar cuenta del paso del análisis del texto al de la escena, entendiendo esta última como una página tridimensional de escritura. Lo que aquí nos proponemos es relacionar todo ello con el avance del pensamiento posmoderno, sobre todo por lo que tiene que ver con la crisis del pensamiento del fundamentum planteada por Lyotard y por otros pensadores, como Vattimo o Baudrillard. Hemos observado que la misma pluralidad que parece investir la escena contemporánea opera, con fuerza semejante, en otros campos del conocimiento, revolucionando la manera de concebir el saber, su transmisión $\mathrm{y}$, de forma todavía más relevante, el ser. El pensamiento posmoderno representa un punto de vista particularmente funcional con respecto al análisis de la puesta en tela de juicio de la razón funcional (Zweckrationalität), hecho que ha interesado tanto a la dramaturgia como al arte «preformativo», adoptando a veces posiciones muy radicales, como el rechazo del teatro como representación.
\end{abstract}

Palabras clave: Escritura escénica, Performance text, Posmodernismo.

\begin{abstract}
Speaking of «escritura escénica» means to show the pluricodic and plurimaterial character typical of theatrical events, as well as to describe the passage of the analysis from the text to the scene, that can be read like a tridimensional page of script. What we propose here is to relate all of this to the advancement of postmodern thought, especially in regard to the crisis of fundamentum thought raised by Lyotard and other philosophers such as Baudrillard and Vattimo. We observed that the same plurality operating in the contemporary scene works in other fields of knowledge, revolutionizing the way of conceiving knowledge, its transmission and above all the perception of identity. Postmodern thought represents a functional point of view allowing a practical analysis of the problematization of questions like the collapse of progressive as achievement, which has interested both the drama and the «performative» art, sometimes taking radical positions, such as the rejection of theater as representation.
\end{abstract}

Keywords: Escritura escénica, Performance text, Postmodernism. 
El concepto y la práctica de la escritura escénica representan unos de los marcos fundamentales para el análisis del teatro del siglo XX. De acuerdo con Patrice Pavis $^{1}$, cabe hablar de escritura escénica allí donde se indique, metafóricamente, la práctica de la puesta en escena, que dispone de técnicas e instrumentos precisos capaces de trasmitir un significado al espectador. El citado estudioso afirma asimismo que la escritura escénica se puede hallar más propiamente donde se prescinda del texto dramatúrgico o más bien, de forma aún más radical, en la ausencia de este último.

De entrada diremos que la problemática que aquí queremos analizar es algo distinta de lo que acabamos de exponer, si bien esto mismo nos interesa al menos en dos aspectos. El primero es la indicación del nacimiento de la dirección como fenómeno anticipador de las complejidades que el concepto de escritura escénica plantea; el segundo es el haber mostrado, en relación con el texto, el punto de ruptura con la práctica precedente. Procediendo por grados, podríamos tratar de hallar los primeros testimonios del término, que se pueden remontar a Roger Planchon (en el curso de un debate sobre Brecht en 1961) y a Bernard Dort ${ }^{2}$ (en sus ensayos críticos sobre el Berliner Ensemble) y que se desarrolla en el seno del análisis de una de las más felices experiencias de creación teatral, teniendo en cuenta que ambos estudiosos revelan, en la interferencia entre escritura dramatúrgica y praxis escénica, el logro más característico de la dirección contemporánea.

La presencia de los primeros testimonios en el contexto del teatro de dirección pone el consecuente interrogante sobre el desarrollo del fenómeno únicamente en los confines de la problemática planteada por este último. Cuando Maurizio Gran$\mathrm{de}^{3}$, contrariamente a lo expuesto arriba, sostiene que en los años setenta la noción de escritura escénica tiende gradualmente a sustituir a la normatividad y a la praxis de la dirección, habla de la sustitución de un modelo lingüístico históricamente determinado por otro diferente, igualmente estructurado.

Hablar de un teatro como sistema de signos sirve a Bartolucci ${ }^{4}$, a Grande o, en el contexto americano, a Kostelanetz ${ }^{5}$ para analizar un teatro que, asumiendo la dimensión escénica como parte central y no ya subordinada al texto, reflexiona sobre su estatuto lingüístico y su propia especificidad.

De esta manera, el teatro empieza a ser definible como un sistema de signos y no ya como un sistema de trasposición de signos (inscribiendo el paso de la significación de la página a la escena). Decir que la escena tiene su propio texto, o mejor que es ella misma un texto, significa no sólo modificar la aproximación al estudio del

\footnotetext{
${ }^{1}$ P. Pavis (1998), p. 386.

${ }^{2}$ Ver E. Copfermann (1969), p. 123, y B. Dort (1967), p. 224.

${ }^{3}$ M. Grande (1990), p. 81.

${ }^{4}$ G. Bartolucci (1968), p. 68-82.

${ }^{5}$ R. Kostelanetz (1980), p. XIII.
} 
teatro sino, sobre todo, suponer una distinta noción de teatro. Es esto, a nuestro parecer, el efecto más relevante que conlleva todo el fenómeno. De hecho, los estudiosos mencionados arriba se encuentran con la necesidad de analizar todo el contexto de la nueva vanguardia, que venía desarticulando y poniendo en cuestión el lenguaje teatral a través de un complejo proceso de redefinición conceptual.

En la misma medida, no se tiene que considerar una casualidad la aparición, en el seno de la semiótica teatral, de conceptos como performance text (según lo entiende Elam $^{6}$ ) o texto espectacular. Para De Marinis ${ }^{7}$, analizar el espectáculo como texto significa subrayar el carácter de pluricódigo y de plurimaterialidad del evento espectacular, siendo este último un texto de textos, un macrotexto. Resumiendo, se podría llegar a sostener que los conceptos de escritura escénica y de texto espectacular tienen en común el mismo sistema de referencia, el paso de los planos de la escritura o del texto a la escena y al espectáculo. El desplazamiento de la significación del texto a la materialidad del hecho teatral significa suponer una escena que funciona, según Grande ${ }^{8}$, como una página tridimensional de escritura.

Hay que subrayar, al igual que hace Mango ${ }^{9}$, que la introducción de conceptos como performance text o escritura escénica no tiene que ser entendida como algo opuesto a un modelo genérico y universal de teatro, sino a un modelo históricamente determinado como el que suponía la disposición jerárquica del texto sobre el evento (y que se llegó a transformar en un código normalizador, hasta generar la equivalencia entre texto dramatúrgico y teatro) ${ }^{10}$.

De manera análoga a lo propuesto anteriormente por las Vanguardias Históricas (especialmente Craig y Appia), que habían elaborado una peculiar concepción de la escena (como elemento fundamental para la refundación de un lenguaje específicamente teatral), en los años sesenta y sobre todo en los setenta del siglo XX se asiste a una reconsideración de los elementos jerárquicos de la escena, siguiendo una actitud que podríamos llamar insurreccional (pensamos, por ejemplo, en el clásico $\mathrm{Pa}$ radise Now del Living Theatre).

Los autores de la nueva vanguardia europea no solamente se encuentran con tener que negar un proyecto dramatúrgico unitario, sino que dejan que la actitud deconstructiva que los mueve llegue a interesar también al espectáculo como «hecho». De esta manera se pueden hallar distintos momentos que pasan de la negación o crítica de la forma del espectáculo al aislamiento y segmentación de los elementos que lo componen, hasta llegar a dejar al descubierto las contradicciones de las instancias representativas. Lo que se niega es la posibilidad misma de la representación

\footnotetext{
${ }^{6}$ K. Elam (1988), p. 54.

${ }^{7}$ M. De Marinis (1982), p. 61.

${ }^{8}$ M. Grande (1990), p. 80.

${ }^{9}$ L. Mango (2003), p. 45.

${ }^{10}$ Para un acercamiento a ese teatro véanse R. Goldberg (1996) y J. Sánchez (1994).
} 
de una realidad unitaria, garantizada por cualquier principio ordenador postulado apriorísticamente, fundamentalmente el texto dramatúrgico.

Un cambio como este ha sido el resultado de la confluencia de numerosos factores en la dramaturgia moderna, como el happening o la performance y el paso del grand recit $\left(\right.$ Lyotard $\left.^{11}\right)$ al pensiero debole (Vattimo ${ }^{12}$ ) dado a la vez en la filosofía posmoderna. Por lo que se refiere al happening, hay que subrayar que el hecho de que el teatro pueda ser reconducido a un conjunto de acciones tomadas en su puro ocurrir (sin ser necesariamente ordenadas por un texto narrativo) ha supuesto en el teatro contemporáneo un acto definitivamente liberador, dejando claro cómo la teatralidad puede ser planteada, antes de nada, como la ocasión de una escritura de la escena que se mueve a lo largo de coordenadas específicas (y más bien espaciales y temporales que textuales).

Hablar de escritura de la escena, además, tiene que hacernos reflexionar sobre el paso (en el análisis y en el planteamiento del hecho teatral) del producto al proceso, siguiendo la misma propuesta que Blanchot ${ }^{13}$ aplica a la literatura: la escritura representa un estadio abierto a lo posible que se contrapone a la obra como formalización definida y límite. En la misma medida, hablar de escritura escénica significa prestar atención al proceso, al hacerse del hecho teatral y, a la vez, la apertura a las posibilidades que el proceso lleva consigo.

Efectivamente, mirando de cerca el fenómeno neovanguardista, notaremos cómo la tendencia a un teatro capaz de hacerse escritura corresponde a una manera de intervención sobre el lenguaje mismo, sobre la persona que lo pone en marcha (el performer) y sobre quien es el receptor de su mensaje (el espectador). Si el teatro de dirección, con Craig como fundador, proponía una síntesis de los lenguajes escénicos (organizados en torno a un principio regulador a través del cual se ordenaban, homogéneamente, los distintos planos del lenguaje), el teatro de la escritura escénica se presenta como juego lingüístico orientado a la contaminación y a la interferencia de los distintos códigos de la escena. El signo se hace autorreferencial y entre el momento escénico y el momento narrativo se produce una disgregación (transformando la historia no en el objetivo de la representación sino en la ocasión de revelar las distintas posibilidades del lenguaje de funcionar como acto de significación).

Así pues, para resumir, el teatro de la escritura escénica supone un aumento exponencial de lo efímero sobre lo predeterminado, de lo plural sobre lo singular y del signo sobre el significado. Por otra parte, moviéndonos dentro de una lógica de ese tipo, podemos ver cómo la misma pluralización y la descentralización que opera en el teatro contemporáneo interesan también al pensamiento sociológico y filosófico,

\footnotetext{
${ }^{11}$ J. F. Lyotard (1979) y (1986).

${ }^{12}$ G. Vattimo y P. A. Rovatti (2010).

${ }^{13}$ M. Blanchot (1988), p. 26.
} 
que ha dado por acabado el fundamentum y ha saludado la llegada de un pensamiento débil, local, gestionado por el juego lingüístico.

Nuestro interés aquí por el pensamiento posmoderno no supone simplemente una voluntad de clasificación o catalogación (tal vez ad excludendum) del teatro definible como posmodernista, según se propone la escuela alemana (como ocurre por estudiosos como Fischter-Lichte ${ }^{14}$ o Schlueter ${ }^{15}$ ). Lo que pretendemos sobre todo es extraer unas características comunes que, según nuestra opinión, han funcionado de forma análoga en ambos sistemas, el pensamiento posmoderno en general y el teatro contemporáneo en particular.

Antes de nada, vamos a ocuparnos de precisar aquellos factores específicos de la posmodernidad, cosa que, sin duda, constituye uno de los temas más relevantes (y también menos comprendidos) de la especulación literaria y filosófica de nuestros días. En efecto, pocos términos se presentan tan problemáticos como los que nos disponemos a analizar, no sólo por la variedad de usos que han tenido ellos mismos sino también por la diversidad de concepciones del fenómeno que denominan ${ }^{16}$. Dado que entendemos que este no es el lugar para un análisis más profundo, nos limitaremos a decir que, a nuestro parecer, tiene razón Lyotard cuando, con la ironía que le caracteriza, sostiene que postmoderno es, probablemente, una palabra pési$\mathrm{ma}^{17}$.

Frente a aquella época del pensamiento que Maffesoli define como posmedieva$\operatorname{lidad}^{18}$ (una modernidad que, utilizando una definición de Auguste Comte, se estructuraría en torno al principio de la reductio ad unum), lo posmoderno supone la desaparición de los grandes relatos legitimadores o metanarraciones ${ }^{19}$, oponiendo a la homogeneización de las mitologías (entre ellas, la Ilustración, el Idealismo y el Marxismo) el juego lingüístico y la narración local. La reductio ad unum de la modernidad se basa, según estos filósofos, en una tríada fundadora: el Individuo, la Historia (como progresión lineal) y la Razón, según sintetiza el mismo Maffesoli ${ }^{20}$.

La desvalorización del fundamentum de las grandes narraciones colectivas lleva consigo la consecuencia por la cual a una verdad absoluta que se tiene que alcanzar

\footnotetext{
${ }^{14}$ E. Fischer-Lichte (1986) y (1988).

${ }^{15}$ J. Schlueter (1998).

${ }^{16}$ La tarea de definir el concepto es todavía objeto de debate entre los que impulsan el estudio del tema. Existen, como han demostrado H. Foster (1986), H. Bertens (1986) e I. Hoesterey (1991) entre muchos otros, distintas perspectivas teóricas sobre la Posmodernidad y su significado. Para algunos, como Jameson, la posmodernidad nunca se podrá entender en su totalidad; F. Jameson (1992), p. 164.

${ }^{17}$ J. F. Lyotard (1982), p. 35.

${ }^{18}$ M. Maffesoli (2003), p. 44.

${ }^{19}$ J. F. Lyotard (1979), p. 32.

${ }^{20}$ M. Maffesoli (2003), p. 47.
} 
(una Zweckrationalität, una razón funcional, diría la escuela de Frankfurt) se contraponen las verdades parciales que conviene vivir.

La diferencia con una historia planteada como algo lineal (una historia finalizada, cabría decir) y el alcance de una narración que se ha vuelto local llevan a reencontrar el sentido de la experiencia en el acto mismo y, más concretamente, a un aumento del valor del significante sobre el significado, de la persona sobre el individuo y del lugar sobre el tiempo. Es decir, lo posmoderno parece llevar a la evidencia de que un pensamiento unidireccional y unidimensional resulta inadecuado para la comprensión de la pluridimensionalidad y la heterogeneidad de nuestra existencia, así como de la tensión existente entre los distintos sistemas experimentados. Sobre todo, si damos la razón a Vattimo, la Posmodernidad considera positiva la liberación de las diferencias, del consenso local y del pensamiento débil.

Debe considerarse, no obstante, la parcialidad de la visión que podemos ofrecer: otros pensadores han llegado a consideraciones muy distintas. Otros pensadores, entre los que cabe destacar a Habermas y Jameson, han llegado a consideraciones muy distintas. Según la opinión de Habermas, efectivamente, la Posmodernidad sería el signo de la crisis en la cual se halla el proyecto cultural de la modernidad, proyecto para el cual él considera todavía necesario luchar, a pesar de las señales que indican su disolución. El pensamiento posmoderno, con su relativismo metodológico y su nihilismo teórico, sería responsable de haber infringido la racionalidad comunicativa de la modernidad cultural, amenazando sus ideales emancipadores ${ }^{21}$. Jameson parece llegar a consideraciones muy parecidas, notando cómo lo posmoderno representa la forma cultural eminente del capitalismo maduro y el síntoma más evidente de su proceso de declive.

En resumen, se podría llegar a sostener que el objeto de la experiencia de la colectividad contemporánea posmoderna no es ya el mundo unitario y «nouménico», sino una realidad local, sensible, fenoménica, garantizada por el juego lingüístico provisional y por la orientación yo-tú fundada en la experiencia de la alteridad (esto es, de la diferencia).

De acuerdo con Baudrillard ${ }^{22}$, un giro subversivo como el que se acaba de describir daría lugar a una era de la simulación y del simulacro, siguiendo una línea análoga a la pretendida por la pintura neofigurativa. Aquí, la invocación a la semejanza funcionaba a la vez como prueba de la desaparición del objeto en su representación y de la puesta en tela de juicio de uno y de otro: el objeto no reenviaría a nada sino a su representación vacía (es algo hiperreal, diría el filósofo). La muerte anunciada de la representación genera como consecuencia directa el paso de un signo que indica algo a un signo que indica que no hay nada (suponiendo, según el filósofo, el paso de la teología de la verdad al simulacro). A un principio de equiva-

\footnotetext{
${ }^{21}$ J. Habermas (1981).

22 J. Baudrillard (2009), p. 66.
} 
lencia entre signo y realidad se opone el signo como reversión y mise à mort de todo referente.

Así pues, no nos parece casual hallar en el teatro de escritura escénica una reversión del orden de procedencia entre signo y significado (signo precedente al significado), opuesta a una visión textocéntrica que proponía un sistema diametralmente opuesto. Es solamente teniendo presente la contingencia del juego lingüístico como se pueden comprender, en toda su consecuencia liberatoria, las experiencias de Robert Wilson, de Pina Baush, de la Raffaello Sanzio o del Wooster Group de Elizabeth Le Compte, por citar algunos nombres.

Intentaremos mostrar ahora brevemente los puntos de contacto entre, por una parte, el cambio de perspectiva que trae consigo el pensamiento posmoderno y, por otra, el teatro de escritura escénica (entendiendo esta, insistimos, como práctica específica e históricamente determinada), es decir, queremos verificar cómo y en qué medida actúan en el teatro los diversos aspectos mencionados más arriba. Nuestra hipótesis es que el cambio de estatus del hecho teatral (que empieza a ser planteado como hecho, precisamente) está influido por la desaparición de las metafísicas, por la caducidad del juego lingüístico, por la provisionalidad del horizonte del consenso y, en fin, por la presencia de un pensamiento que ya no funda si no que ocurre.

A grandes rasgos podríamos enumerar los siguientes puntos clave:

a. Polidimensionalidad, en lugar de la creencia en un mundo unitario y cohesivo.

b. Pensamiento y acción contingentes.

c. Desaparición de la regla absoluta.

d. Predominio de la pequeña narración sobre el grand recit.

e. Consenso local y juego lingüístico en oposición al textocentrismo.

f. Puesta en tela de juicio del valor lineal en favor de estructuras fragmentadas y collage.

Al referirnos a la escritura escénica, hemos aludido, aunque de pasada, al movimiento progresivo que transporta a la escena teatral contemporánea desde un teatro que podríamos llamar del texto a uno en el que todos los elementos que la componen (escenografía, performer, espacio, luminotecnia) son llamados a interactuar sin presuponer una jerarquización. Simplemente desde este acercamiento «superficial» es posible observar una multiplicación de las realidades llamadas a manifestar (y a manifestarse) en escena: ¿cómo no ver en la desaparición del carácter regulador del texto un duro golpe asestado por la pequeña narración al pensamiento del fundamentum? A propósito de esta desaparición, Lorenzo Mango habla de una deconstrucción. $\mathrm{Y}$ es que el proceso de construcción que cierto teatro contemporáneo ha venido experimentando desde el happening hasta nuestros días ha supuesto una puesta a cero de los principios constitutivos de la escena (a partir del relato dramático y de la interpretación psicológica de los caracteres), renunciando a utilizar el 
texto literario como un dispositivo ordenador del espectáculo, así como a disponerse siguiendo un orden de tipo lineal ${ }^{23}$ garantizado por la obra preexistente. Se consigue así dejar al margen o poner en tela de juicio la pretensión de transcodificar el texto verbal en el texto espectacular, que funciona, por el contrario, como material contrapuesto a los demás elementos de la escena. Son estos diversos códigos, de hecho, los que tienen que encargarse del proceso de significación que ya no es preexistente o postulado a priori sino medio de descubrimiento del significado mismo (signo precedente al significado, hemos dicho con Mango). Está claro, pues, que no será ya posible ver la obra de autores como Kantor, Brook, Barba, Bausch, Lepage o Fabre, o la de grupos como Raffaello Sanzio, Wooster Group o Els Joglars, si no es con la óptica de una pluralización incesante de los significantes y de una localización de la experiencia que parece investir tanto la realidad como la visión que el artista ofrece (estética).

El final del textocentrismo, que podríamos entender a estas alturas, como una ulterior prueba del colapso metafísico, ofrece al teatro (en la misma medida en la que el final del fundamentum se había hecho positivamente subversivo para el sujeto social) la ocasión de experimentar el abandono de un único centro (garantizado por el texto) a favor de la exploración de un multicódigo. Sin embargo, la pluralización no interesa únicamente a la dramaturgia, sino que concierne a la escena contemporánea en muchas facetas y aspectos que van desde la práctica del collage (intertextualidad) o del ready made a la interculturalidad o intermedialidad, de la exhibición de cuerpos alterados (deformaciones, cyborg, cuerpo-maquina) a la teatralización de espacios no teatrales (teatro de calle, happening, Open Theatre).

Por una cuestión de espacio, no podemos ahora tratar estos aspectos que también testimonian la necesidad de referirse a una realidad que se ha hecho babélica, como notaba Wittgenstein ${ }^{24}$ hablando del lenguaje. Nos limitaremos a decir que el teatro de la escritura escénica, el planteamiento de un performance text, así como el teatro posdramático planteado por Lehmann ${ }^{25}$, nos parecen la consecuencia directa de aquel pensamiento de la complejidad ${ }^{26}$ que ya no puede tener la ambición de un control o dominio de la realidad, sino sólo la de entablar con ella un diálogo o una negociación (el consenso local y débil del cual habla la filosofía posmoderna).

Para acabar, nos permitiremos observar que el teatro contemporáneo, al hacer visibles los límites de la representación, parece subrayar una vez más la imposibilidad de una traducción transparente, armónica, ilusionista. Y es que sin duda tenía razón Lyotard cuando sostenía que un artista posmoderno se encontraba en la situación de un filósofo: la obra que se lleva a cabo no está sostenida por reglas preestablecidas,

${ }^{23}$ V. Valentini (1989), p. 15.

${ }^{24}$ L. Wittgenstein (1974), p. 17.

${ }^{25}$ H. T. Lehmann (1999). Véase también O. Cornago (2006).

${ }^{26}$ E. Morin (1994), p. 49. 
que puedan ser juzgadas a través de un juicio determinante, a través de la aplicación de categorías comunes ${ }^{27}$. Son esas mismas reglas y esas mismas categorías lo que buscan la obra o el texto, y, por tanto, ellas tienen propiedad de «evento». Efectivamente, el teatro comprometido de la Posmodernidad es un teatro de preguntas más que de respuestas, como nota Carlos Marqueríe cuando afirma: «Mi mirada es política, pero la diferencia es que yo no propongo soluciones, no sé si las hay» ${ }^{28}$, afirmación que parece duplicar especularmente las análogas de Bob Wilson ${ }^{29} \mathrm{o}$ de Claudia Castellucci ${ }^{30}$.

Si es verdad que la «pluralidad es el término clave de la posmodernidad», como hace constar Welsch ${ }^{31}$, esto vale también si tomamos como ejemplo, con Marqueríe, algunos de los autores españoles más representativos de los ochenta y noventa: Sergi Belbel, Carles Battle i Jordá, Angélica Lidell, Rodrigo García, Borja Ortiz de Gondra, Francesc Pereira o Antonio Álamo, entre otros. Esos artistas, como sabemos, comparten una experiencia teatral que está marcada por la desconfianza hacia la función comunicativa, epistemológica y perceptiva del lenguaje así como por las utopías políticas del pasado. Ese conjunto de autores se caracteriza por una deconstrucción de las acciones dramáticas a través el juego intertextual (inclusión de imágenes provenientes del cine, el cómic, el videoclip, la televisión) y por la búsqueda de nuevas posibilidades de relación tanto con el texto dramático como con el escénico $^{32}$.

${ }^{27}$ J. F. Lyotard (1986), p. 24.

${ }^{28}$ D. Landra (1993), p. 26.

${ }^{29}$ «I'm an artist, not a philosopher. I don't make meanings. I make art. The responsibility of an artist is not to say what something means, but to ask "What does it mean?" The only reason to do a play is because you don't understand it. The moment you understand a work of art, it's dead for you. The last moment in any play should be a question. What happened? What was said? What is this? A play doesn't conclude. It should stay open ended. The last word must be a beginning, a door opening, not closing. A play is not a lecture in a classroom. I don't dictate meaning to the viewer. Theatre that imposes an interpretation is aesthetic fascism»; A. Holmberg (1996), p. 61.

${ }^{30}$ «La creazione non è la risposta ad una domanda di salvezza, ma, al contrario, essa è un'altra domanda che si pone rispetto ad una risposta di salvezza che abbiamo appena dato e che è, per forza, insoddisfacente alla prova della durata. Non si può sopportare per più di cinque minuti»; R. Castellucci, Ch. Guidi y C. Castellucci (2001), p. 286.

${ }^{31}$ W. Welsch (1991), p. XV.

${ }^{32}$ Según Floeck «el teatro español actual puede integrarse fácilmente en la corriente del teatro postmoderno internacional, pero con la particularidad de que en él postmodernidad y compromiso político forman una unión coherente». Y sigue: «El fuerte compromiso político del teatro español actual se destacó también en las contribuciones del Coloquio Internacional "Teatro y Sociedad en la España actual", celebrado en septiembre de 2003 en la Universidad de Giessen (Floeck/Vilches de Frutos 2004). En mi contribución para este coloquio intenté demostrar que las nociones de postmodernidad y compromiso no se excluyen mu- 
Ese teatro representaría, en nuestra opinión, la demostración de que el posterior regreso a lo textual y a formas de representación basadas también en la realidad no ha significado un retorno ni al teatro mimético tradicional ni a una concepción de los textos teatrales como "escritura literaria», siendo estos últimos caracterizados por una potencialidad teatral ya inscrita de antemano.

Kitsch, pastiche ${ }^{33}$, hibridación entre géneros y collage son sólo algunas de las marcas que atestiguan la presencia y la intensidad de las prácticas posmodernas en el teatro español y europeo de los ochenta y noventa, mientras sus soluciones espectaculares en la praxis escénica (pensamos en grupos como La Fura dels Baus) funcionan como prueba del cambio profundo que el concepto y la práctica de la escritura escénica ha producido en el teatro.

No obstante la brevedad y la parcialidad de nuestro acercamiento, pensamos que solamente teniendo en cuenta el valor desestabilizador de la escritura escénica y de lo posmoderno se puedan comprender experiencias rompedoras como las citadas, experiencias que han logrado, dejando al descubierto las contradicciones de las instancias representativas, hacer del espectáculo el lugar para poner en tela de juicio las nociones de significación y lenguaje, una cuestión aún hoy abierta.

\section{OBRAS CITADAS}

BAUDRILlARD, Jean: Simulacri e impostura, Milano, PiGreco Edizioni, 2009.

BARTOLUCCI, Giuseppe: La scrittura scenica, Roma, Lerici, 1968.

BERTENS, Hans: «The Postmodern Weltanschauung and its Relation to Modernism:

An Introductory Survey», en Approaching Postmodernism: Papers Presented at a Workshop on Postmodernism (Utrech, del 21 al 23 septiembre), Amsterdam, John Benjamins Publishing, 1986, pp. 9-51.

BLANCHOT, Maurice: L'espace littéraire, Paris, Gallimard, 1988.

CAstellucCI, Romeo; Guidi, Chiara; y CASTEllucCI, Claudia: Epopea della polvere, Il teatro della Societas Raffaello Sanzio 1992-1999, Amleto, Masoch,

Orestea, Giulio Cesare, Genesi, Milano, Ubulibri, 2001.

CoPfERmanN, Emile: Planchon, Lausanne, Le Cité, 1969.

tuamente. Además, con esta tendencia a combinar una estética postmoderna con un compromiso político, el teatro español no se opone al teatro internacional. Sobre todo los grandes modelos internacionales del teatro contemporáneo de la Península Ibérica, desde Harold Pinter hasta Heiner Müller y desde David Mamet hasta Bernard-Marie Koltès, muestran rasgos parecidos»; W. Floeck (2004), p. 50.

${ }^{33} \mathrm{H}$. Foster ve el pastiche como el «signo oficial» del posmodernismo neoconservador (1986), p. 127, y lo acusa de resolver falsamente «conflictos entre formas de arte y entre modos de producción»; Foster, (1986), p. 16. 
CORNAGO, Óscar: «Teatro postdramático: Las resistencias de la representación», en José A. Sánchez (ed.), Artes de la escena y de la acción en España 1978-2002, Cuenca, UCLM, 2006, pp. 165-179

DE MARINIS, Marco: Semiotica del teatro. L'analisi testuale dello spettacolo, Milano, Bompiani, 1982.

DORT, Bernard: Teatro pubblico, Padova, Marsilio, 1967.

ECO, Umberto: Opera aperta, Milano, Bompiani, 2000.

ElAM, Keir: Semiotica del teatro, Bologna, Il Mulino, 1988.

FISCHER LICHTE, Erika: «Jenseits der Interpretation. Anmerkungenzum Text von Bob Wilsons/Heiner Müllers, 'the CIVIL warS'», en Albrecht Schöne (ed.), Kontroversen, alte und neue, Akten des VII. Internationalen GermanistenKongresses, Göttingen, Tubinga, 1986, pp. 191-201.

: «Intercultural Aspects in Postmodern Theatre», en The Play out of Context, Cambridge, Cambridge University Press, 1988, pp.173-185.

FLOECK, Wilfried: «El teatro actual en España y Portugal en el contexto de la postmodernidad», Iberoamericana IV, 14 (2004), pp. 47-67.

Foster, Hal: The Anti-Aesthetic: Essay on Postmodern Culture, Port Townsend, Wash, Bay Press, 1986.

GoldBerg, Roselee, Performance Art, Barcelona, Destino, 1996.

GRANDE, Maurizio: «La regia come scrittura di scena», en Gli anni di Peter Brook, Milano, Ubulibri, 1990.

HABERMAS, Jürgen: «Moderno, postmoderno e neoconservatorismo», Alfabeta, 22 (1981), pp. 15-17.

HOESTEREY, Ingeborg: Zeigeist in Babel: The Postmodernist Controversy, Bloomington, Indiana University Press, 1991.

HOLMBERG, Arthur: The theatre of Robert Wilson, Cambridge, Cambridge University Press, 1996.

JAMESON, Fredric: «Postmodernism and Consumer Society», en Modernism /Postmodernism, New York, Longman, 1992, pp. 163-179.

KostelanetZ, Richard: The Teatre of Mixed-Means, New York, RK Editions, 1980.

LANDRA, David: «Conversación con el teatro alternativo», Primer Acto, 248 (1993), pp. 15-26.

Lehmann, Hans-Thies: Postdramatisches Theater. Verlag der Autoren, Frankfurt am Main, Verlag der Autoren, 1999.

LYOTARD, Jean François: La condition postmoderne: rapport sur le savoir, Paris, Les Editions de Minuit, 1979.

: La pittura del segreto nell'epoca postmoderna. Barruchello, Milano,

Feltrinelli, 1982.

: Le Postmoderne expliqué aux enfants, Paris, Editions Galilée, 1986.

MAFFESOLI, Michel: Notes sur la postmodernité, Paris, Editions du Félin, 2003. 
MANGO, Lorenzo: La scrittura scenica. Un codice e le sue pratiche nel teatro del Novecento, Roma, Bulzoni, 2003.

MORIN, Edgar: «Le vie della complexita», en Gianluca Bocchi y Mauro Ceruti (eds.), La sfida della complessità, Milano, Feltrinelli, 1994, 31-54.

PAVIS, Patrice: Dizionario del teatro, Bologna, Zanichelli, 1998.

SÁnCHEZ, José A., Dramaturgias de la imagen, Cuenca, Universidad de Castilla-La Mancha, 1994.

SCHLUETER, June: «Theatre», en Stanley Trachtenberg (ed.), The Postmodern Moment. A Handbook of Contemporary Innovation in the Arts, London, Greenwood Press, 1998, pp.209-228.

Valentini, Valentina: Dopo il teatro moderno, Milano, G. Politi, 1989.

Vattimo, Gianni, y Rovatti, Pier Aldo: Il pensiero debole, Milano, Feltrinelli, 2010.

WELSCH, Wolfgang: Unsere postmoderne Moderne, Weinheim, VCH, 1991.

WITTGENSTEIN, Ludwig: Ricerche filosofiche, Torino, Einaudi, 1974. 